\title{
Endoskopi eğitiminin hastalardaki kaygı düzeyine etkisi
}

\author{
Effect of anxiety level of education in patients of endoscopy
}

\author{
Özlem Ceyhan, Pınar Tekinsoy Kartın, Sultan Taşcı
}

Özet

Amaç: Bu çalışmada üst endoskopi uygulanacak bireylere verilen eğitimin bireylerin kaygı düzeyine etkisini belirlemek amaçlanmıştır.

Gereç ve Yöntem: Araştırma bir üniversite hastanesinin endoskopi ünitesinde ilk kez üst endoskopik işlem uygulanacak, 40'ı çalışma, 40'ı kontrol, 80 birey üzerinde yürütülmüştür.

Bulgular: Araştırma kapsamına alınan bireylerin yaş ortalaması 43.5 11.7 olup, \%60.0'ı kadın, \% 45.0' ilköğretim mezunu, \%56.3'ü daha önce hastanede yatmış, \%43.8'i cerrahi işlem geçirmiş vakalardı. İşlem öncesi eğitim verilen gruptaki bireylerin işlem sonrasında durumluk kaygılarının işlem öncesine göre anlamlı olarak azaldığı saptanmıştır $(p<0.001)$. Eğitim verilmeyen gruptaki bireylerde ise durumluk kaygı puanı işlem sonrasında işlem öncesine göre azaldığı, fakat bu azalmanın anlamlılık gösterecek düzeyde olmadığı belirlenmiştir $(p>0.05)$. Sonuç:Çalışmada hastalara işlem öncesi verilen eğitimin durumluk kaygıyı azaltmada etkili olduğu saptanmıştır.

Anahtar sözcükler: Endoskopi, eğitim, kaygı

Ceyhan Ö, Tekinsoy-Kartın P, Taşcı S. Endoskopi eğitiminin hastalardaki kaygı düzeyine etkisi. Pam Tıp Derg 2018;11(3);293-300.

\begin{abstract}
Purpose: In this study, it was aimed to determine the effect of education given to the individuals who would be given upper endoscopy on the level of anxiety of the individuals.

Materials and methods: The study was conducted on an endoscopy unit of a university hospital for the first time to perform upper endoscopic procedure, 40 studies, 40 controls, 80 individuals.

Results: The average age of the subjects included in the study was $43.5 \pm 11.7,60.0 \%$ were female, $45.0 \%$ were primary school graduates, $56.3 \%$ were previously hospitalized and $43.8 \%$ had undergone surgical procedures. It was found that the state anxiety of the individuals in the pre-treatment group decreased significantly after the procedure $(p<0.001)$. In the uneducated group, the state anxiety score decreased after the procedure compared to the pre-treatment, but it was determined that this decrease was not significant enough $(p>0.05)$. Conclusion: It was determined that pre-treatment training in the study was effective in decreasing the state anxiety.
\end{abstract}

Key words: Endoscopy, education, anxiety

Ceyhan Ö, Tekinsoy-Kartın P, Taşcı S. Effect of anxiety evel of education in Patients of Endoscopy. Pam Med J 2018;11(3):293-300.

Özlem Ceyhan, Dr.Öğr.Üyesi, Erciyes Üniversitesi, Sağlık Bilimleri Fakültesi, KAYSERI, e-posta:ozlemceyhan06@gmail.com (orcid.org/0000-00021869-8713) (Sorumlu yazar)

Pınar Tekinsoy Kartın, Dr.Öğr.Üyesi, Erciyes Üniversitesi, Sağlık Bilimleri Fakültesi, KAYSERI, e-posta:ptekinsoy@erciyes.edu.tr (orcid.org/00000002-9977-158X)

Sultan Taşcı, Prof.Dr., Erciyes Üniversitesi, Sağlık Bilimleri Fakültesi, KAYSERI, sultant@erciyes.edu.tr (orcid.org/0000-0002-8039-1966) 


\section{Giriş}

İçi boş organların ya da kanal şeklindeki yapıların içlerinin özel aletler yardımıyla incelenmesine endoskopi adı verilir. Günümüzde en sık uygulanan endoskopik prosedürlerden birisi üst Gastro İntestinal Sistem (GIS) endoskopisidir. Üst GiS endoskopisi ile özefagus, mide ve duodenum incelenir ve bu alanlara yönelik gereken diagnostik ve terapötik işlemler yapılabilir [1, 2].

Gelişen teknoloji ile birlikte tanı ve tedavide önemi giderek artan endoskopi işleminde komplikasyon görülme yüzdesi de oldukça düşüktür. Bu gelişmeler sayesinde, günümüzde gastroenteroloji kliniklerine başvuran hastalara tanısal ya da tedaviye yönelik olarak giderek artan sayıda endoskopik girişimler uygulanmaktadır [3-7].

Endoskopi, hastaya yönelik girişimsel bir işlem olduğu için, işlem sırasında öğürme, bulantı hissi, karında şişkinlik ve ağrı seklinde şikayetler olabilmektedir [8-9]. Bunun için endoskopi uygulanacak hastaların işlem öncesi endoskopiye hazırlanması önemlidir. Bunda amaç hasta ve endoskopi ekibi için güvenli, rahat, efektif bir işlem gerçekleştirmektir [10].

Endoskopi yapılma endikasyonu saptanan hastalarda endoskopi planlanırken öncelikle öykü ve fizik muayenesi ile iyi bir şekilde gözden geçirilmelidir. Öyküde işlem performansını etkileyebilecek daha önce geçirilen gastrointestinal cerrahi varlığı, ilaç alerjisi varlığı, kardiyak ve solunumsal yakınmaların olup olmadığı, koagülasyon bozukluğu varlığı, antikoagülan veya antitrombosit tedavi alıp almadıkları özellikle sorgulanmalıdır [1, 8].

İşlem öncesinde hastalara endoskopi ve riskleri hakkında bilgi verilmeli, sözlü ve yazılı olarak bilgilendirilmiş rızaları alınmalıdır [11]. Endoskopik işlemler hakkında yeterli bilgi verilmemesi kişide anksiyete, korku, endişe gibi durumlar oluşturmakta ve hastanın uyumunu güçleştirmekte, toleransını azaltmaktadır. Bu durum hasta ile endoskopi ekibi arasındaki iletişimi zedelemekte, işlemin konforunu azaltmakta ve ekibin rahat çalışmasını engellemektedir. İşleme bağlı oluşabilecek anksiyete, ağrı ve korkular uygun bir yaklaşım, yeterli bilgilendirme, uygun bir ortam ve işlem öncesi uygulanacak sakinleştirici ilaçlarla giderilebilmektedir [8, 12].
$\mathrm{Bu}$ çalışma ile endoskopi yapılacak kişilerin işlem hakkında planlı olarak bilgilendirilmeleri sonucu kaygı düzeylerindeki değişiklikler saptanarak, elde edilen sonuçlar ile hasta eğitiminin önemine dikkat çekmek amaçlanmaktadır.

\section{Gereç ve Yöntem}

Araştırma bir üniversite hastanesinin Endoskopi Ünitesi'nde yapılmıştır. Çalışmaya İlk kez üst endoskopik işlem uygulanacak, 40'ı çalışma, 40'ı kontrol, 80 birey alınmıştır. Her iki grupta cinsiyet, yaş ve eğitim durumu özellikleri benzer tutulmuştur. Çalışmada bireylerin sosyo-demografik özelliklerini ve önceden bilgi alma durumlarını belirleyen 21 sorudan oluşan anket formu ve durumluk (işleme ilişkin)sürekli kaygı düzeylerini ölçen Spielberg ve arkadaşları tarafından geliştirilen, Türkiye'deki geçerlilik ve güvenilirliği Le Compte ve Öner tarafından yapılan Durumluk-Sürekli Kaygı Envanteri (DSKE) kullanılmıştır [13]. DSKE her biri 20 madde içeren iki ölçekten oluşmaktadır. Durumluk Kaygı Ölçeği, bireyin belirli bir anda ve belirli koşullarda kendini nasıl hissettiğini belirler ve her madde için "hiç", "biraz", "çok" ve "tamamıyla" şıklarından biri işaretlenir. Sürekli Kaygı Ölçeği ise; bireyin içinde bulunduğu durum ve koşullardan bağımsız olarak genellikle kendini nasıl hissettiğini belirler ve her madde için "hemen hiçbir zaman", "bazen", "çoğu zaman" ve "hemen her zaman" şıklarından birinin işaretlenmesi istenir. Ölçeklerde doğrudan ve tersine çevrilmiş sorular yer almaktadır. Durumluk Kaygı Ölçeğinde 10 tane, Sürekli Kaygı Ölçeğinde 7 tane tersine çevrilmiş soru bulunmaktadır. İki ölçekten de alınan puanlar 20-80 arasında değişmektedir. Puanın artması kaygının arttığını gösterir ve 60 puan üzeri patolojik kaygıyı ifade etmektedir.

Çalışma grubundaki bireylere işlemden önce ünitede çalışan hemşireler tarafından işlemi açıklayıcı yazılı eğitim materyali ile bire bir eğitim verilmiştir. İşlemden önce ve sonra DSKE bireylere birebir hemşireler tarafından uygulanmıştır. Kontrol grubuna ise eğitim verilmeden işlem öncesi ve sonrası DSKE ile kaygı düzeyleri değerlendirilmiştir.

Elde edilen veriler SPSS 22.0 paket programı yardımıyla değerlendirilmiş, istatistiksel değerlendirmede bağımsız iki örnek $t$ testi, bağımlı iki örnek $t$ testi ve tek yönlü varyans 
analizi uygulanmıştır. Fark çıkan gruplarda çoklu karşılaştırmalar Tukey ve Holm Sidak testleri ile yapılmıştır. Değerlendirmelerde $p<0.05$ düzeyi anlamlı olarak alınmıştır.

Çalışma 2008'de Helsinki bildirgesinin ilkelerine (World Medical Associations Declaration of Helsinki. 2008) uygun olarak yürütülmüştür. Çalışmanın yapılabilmesi için akademik kurul izni, kurum izni ve katıımcılarda yazılı sözlü onam formu alınmıştır.

\section{Bulgular}

Araştırma kapsamına alınan bireylerin, yaş grupları, öğretim durumu, çalışma ve gelir durumuna göre dağılımında, arastırma kapsamına alınan 80 bireyin yaş ortalaması $43.51 \pm 11.69$ 'dur. Bireylerin \%60.0'ı kadın, \%42.5'i 40-49 yaş grubunda, \%45.0' ו ilköğretim mezunu, \%88.8'i evli , \%53.8'i çalışan, \%57.5'i yeşil kartlı ve \%83.8'i orta gelir düzeyindedir (Tablo 1).

Araştırma kapsamına alınan bireylerin, hastalık ve bilgi durumlarına bakıldığında, deney grubundaki bireylerin \%42.5'inin Gastrit, kontrol grubundakilerin ise \%40.0'ının Peptik Ösefajit ön tanısı ile başvurdukları ve deney grubundaki bireylerin \%47.5'inin, kontrol grubundakilerin \%65.0'ının daha önce hastane deneyimi yaşadıkları saptanmıştır. Ayrica deney ve kontrol grubundaki bireylerin yaklaşık yarısının daha önce girişimsel işlem deneyimleri olduğu bulunmuştur. Çalışmada deney grubundaki bireylerin \%35.0'ının, kontrol gurubundakilerin ise $\% 37.5$ 'inin daha önce işleme ilişkin bilgi aldıkları, her ki grupta da bilgi alan kişilerin çoğunluğunun bilgiyi doktorlardan aldıkları tespit edilmiştir (Tablo 2).

Tablo 1. Bireylerin tanımlayıcı özellikleri

\begin{tabular}{lcc}
\hline ÖZELLiKLER & Sayı & $\%$ \\
\hline Cinsiyet & 48 & 60 \\
Kadın & 32 & 40 \\
Erkek & & \\
Yaş Grupları & 8 & 10.0 \\
$20-29$ & 10 & 12.5 \\
$30-39$ & 34 & 42.5 \\
$40-49$ & 28 & 35.0 \\
$50+$ & & \\
Eğitim Durumu & 10 & 12.5 \\
Okuma yazma bilmiyor & 36 & 45.0 \\
Illköğretim & 34 & 42.5 \\
Lise ve üzeri & & \\
Medeni durumu & 9 & 11.3 \\
Bekar & 71 & 88.7 \\
Evli & & \\
Çalışma Durumu & 43 & 53.8 \\
Çalışan & 37 & 46.2 \\
Çalışmayan & & \\
Sosyal Güvence Durumu & 6 & 7.5 \\
Emekli Sandığı & 28 & 35.0 \\
SSK-Bağ-kur & 46 & 57.5 \\
Yeşil Kart & & \\
Gelir Durumu & 13 & 83.7 \\
İyi & 67 &
\end{tabular}


Tablo 2. Deney ve kontrol grubundaki bireylerin hastalık ve bilgi durumları

\begin{tabular}{|c|c|c|c|c|}
\hline \multirow{3}{*}{ Hastalıkla ilgili özellikler } & \multicolumn{4}{|c|}{ Gruplar } \\
\hline & \multicolumn{2}{|c|}{ Deney } & \multicolumn{2}{|c|}{ Kontrol } \\
\hline & Sayı & $\%$ & Sayı & $\%$ \\
\hline \multicolumn{5}{|l|}{ Ön tanı } \\
\hline Gastrit & 17 & 42.5 & 4 & 10.0 \\
\hline Mide Ağrısı & 10 & 25.0 & 7 & 17.5 \\
\hline Peptik Ösefajit & 10 & 25.0 & 16 & 40.0 \\
\hline Diğer & 3 & 7.5 & 13 & 32.5 \\
\hline \multicolumn{5}{|c|}{ Daha önce hastaneye yatma durumu } \\
\hline Yatan & 19 & 47.5 & 26 & 65.0 \\
\hline Yatmayan & 21 & 52.5 & 14 & 35.0 \\
\hline \multicolumn{5}{|c|}{$\begin{array}{l}\text { Daha önce girişimsel işlem geçirme } \\
\text { durumu }\end{array}$} \\
\hline & 16 & 40.0 & 19 & 47.5 \\
\hline $\begin{array}{l}\text { Olan } \\
\text { Olmayan }\end{array}$ & 24 & 60.0 & 21 & 52.5 \\
\hline \multicolumn{5}{|c|}{ Daha önce bilgi alma durumu } \\
\hline Alan & 14 & 35.0 & 15 & 37.5 \\
\hline Almayan & 26 & 65.0 & 25 & 62.5 \\
\hline Bilgi aldığı kişi & \multicolumn{2}{|c|}{$\mathrm{n}: 14$} & \multicolumn{2}{|c|}{$\mathrm{n}: 15$} \\
\hline Doktor & 10 & 71.5 & 8 & 53.3 \\
\hline Hemşire & - & - & 4 & 26.7 \\
\hline Arkadaş-komşu & 4 & 28.5 & 3 & 20.0 \\
\hline
\end{tabular}

Araştırma kapsamına alınan deney ve kontrol grubundaki bireylerin durumluluk kaygı düzeylerinde, deney grubundaki bireylerin işlem öncesi durumluluk kaygılarının eğitimle birlikte işlem sonrasında ileri derecede anlamlı olarak azaldığı saptanmıştır $(p<0.01)$. Eğitim verilmeyen kontrol grubundaki bireylerin ise işlem sonrasında durumluk kaygıları işlem öncesi ile minimal düzeyde azalma göstermiştir $(p>0.05)$. Deney ve kontrol grubundaki bireylerin sürekli kaygı düzeylerinde, deney grubunun işlem sonrası sürekli kaygıları işlem öncesine göre azalmış, kontrol grubunda ise işlem sonrasında işlem öncesine göre minimal düzeyde azalma gözlenmiştir. İşlem öncesi ve sonrası sürekli kaygı puan ortalamaları arasındaki bu farklılık istatistiksel açıdan anlamlı değildir ( $p>0.05)$ (Tablo 3).

Araştırma kapsamına alınan deney ve kontrol grubundaki bireylerin, cinsiyetlerine göre işlem öncesi ve sonrası durumluk-sürekli kaygı puan ortalamalarına bakıldığında; erkeklerin kaygı puanlarının kadınlara göre daha düşük olduğu saptanmıştır. Deney grubunda işlem sonrası durumluk-sürekli kaygı puanları her iki cinsiyette de azalırken, kontrol grubundaki erkeklerde işlem sonrasında durumluk kaygı, kadınlarda ise sürekli kaygı puanı artmıştır $(p>0.05)$. Araştırma kapsamındaki deney ve kontrol gruplarında işlem öncesi ve sonrası durumluk ve sürekli kaygılarına yaş gruplarına göre bakıldığında, her iki grupta da 20-29 yaş grubundaki bireylerin kaygıları diğer yaş gruplarına göre yüksek bulunmuştur $(p>0.05)$.

Deney ve kontrol grubundaki bireylerin eğitim durumuna göre işlem öncesi ve sonrası durumluk-sürekli kaygı puanlarına bakıldığında, durumluk kaygılarının tüm gruplarda işlem sonrasında azalma gösterdiği saptanmıştır $(p>0.05)$. Sürekli kaygıda ise hem çalışma hem de kontrol grubundaki bireylerin işlem sonrasında kaygıları azalırken, deney grubundaki bu azalmanın lise ve üzeri eğitime sahip olan gruptan kaynaklandığı saptanmıştır $(p<0.05)$. Sadece kontrol grubundaki okuma yazma bilmeyen bireylerin işlem sonrasında sürekli kaygıları artmıştır (Tablo 4). 
Tablo 3. Deney ve kontrol grubundaki bireylerin işlem öncesi ve sonrası durumluk/Süreklilik kaygı puan ortalamaları

\section{Durumluk Kaygı}

\begin{tabular}{|c|c|c|c|c|}
\hline Gruplar & $\mathrm{n}$ & $\begin{array}{l}\text { İşlem Öncesi } \\
\text { (C } \pm \text { SD) }\end{array}$ & $\begin{array}{l}\text { İşlem Sonrası } \\
\text { (C } \pm \text { SD) }\end{array}$ & $p$ \\
\hline Deney & 40 & $51.67 \pm 7.64$ & $45.25 \pm 6.53$ & 0.00 \\
\hline \multirow[t]{2}{*}{ Kontrol } & 40 & $47.75 \pm 10.85$ & $47.25 \pm 7.13$ & $>0.05$ \\
\hline & \multicolumn{4}{|c|}{ Sürekli Kaygı } \\
\hline Deney & 40 & $49.20 \pm 6.02$ & $47.85 \pm 6.16$ & $>0.05$ \\
\hline Kontrol & 40 & $46.65 \pm 7.45$ & $46.30 \pm 7.79$ & $>0.05$ \\
\hline
\end{tabular}

Tablo 4. Deney ve kontrol grubundaki bireylerin eğitim durumlarına göre sürekli kaygı puan ortalamaları

\begin{tabular}{|c|c|c|c|c|c|}
\hline \multirow[b]{3}{*}{ Eğitim Durumu } & & \multicolumn{4}{|c|}{ Sürekli Kaygı } \\
\hline & & \multicolumn{2}{|c|}{ Deney Grubu } & \multicolumn{2}{|c|}{ Kontrol Grubu } \\
\hline & $\mathbf{n}$ & $\begin{array}{l}\text { İşlem Öncesi } \\
\text { (C } \pm \text { SD) }\end{array}$ & $\begin{array}{c}\text { İşlem Sonrası } \\
\text { (C } \pm \text { SD) }\end{array}$ & $\begin{array}{l}\text { İşlem Öncesi } \\
\text { (C } \mathbf{\pm S D})\end{array}$ & $\begin{array}{l}\text { İşlem Sonrası } \\
\text { (C } \pm \text { SD) }\end{array}$ \\
\hline $\begin{array}{l}\text { Okuma yazma } \\
\text { bilmiyor }\end{array}$ & 5 & $52.00 \pm 3.53$ & $49.60 \pm 5.31$ & $48.60 \pm 6.54$ & $50.40 \pm 4.66$ \\
\hline İlköğretim & 18 & $51.61 \pm 5.44$ & $50.77 \pm 5.96$ & $47.61 \pm 6.23$ & $46.27 \pm 6.82$ \\
\hline Lise ve üzeri & 17 & $45.82 \pm 5.72$ & $44.23 \pm 4.82$ & $45.05 \pm 8.85$ & $45.01 \pm 9.30$ \\
\hline$p$ & & $<0.01$ & $<0.05$ & $>0.05$ & $>0.05$ \\
\hline
\end{tabular}

Araştırma kapsamına alınan deney grubundaki bireylerin işlem için başvuru ön tanılarında mide ağrısı ile gelenlerin durumluk kaygısı diğer tanıya sahip gruplara göre yüksek bulunurken, kontrol grubundaki bireylerde gastrit tanısı alanların sürekli kaygıları daha yüksek bulunmuştur $(p>0.05)$. Deney ve kontrol grubundaki bireylerin daha önce işleme yönelik bilgi alma durumlarına göre kaygı düzeylerine bakıldığında, her iki grupta da durumluk-sürekli kaygı işlem sonrasında azalma gösterirken, aralarındaki fark anlamlıık göstermemiştir $(p>0,05)$. Deney grubunda bilgi alan bireylerin işlem öncesi durumluk kaygıları daha yüksek düzeyde bulunmuştur.

\section{Tartışma}

Anksiyete, hastalık ya da hastanede bulunma durumunda ortaya çıkan korku ve endişe durumudur. Tanı aşamasında yapılan testler de hastalar için anksiyete(kaygı) kaynaklarından biridir. Endoskopik inceleme yapılacak hastaların da işlemle ilgili gereksinimlerinin karşılanmaması nedeniyle, yoğun anksiyete ve korku yaşadıkları bilinmektedir [14]. Hasta bilgilendirme, hastanın anksiyete ve stresini azaltmada en önemli ve etkili uygulamadır. Yapılan çalışmalar tanı işlemleri öncesinde hasta bilgilendirmenin girişime bağıı oluşan anksiyete düzeyini düşürdüğünü göstermektedir. $\mathrm{Bu}$ nedenle çalışmamızda, üst gastrointestinal endoskopi işleminde bilgilendirmenin hastaların anksiyete düzeyine etkisi incelenmiştir.

Endoskopi tanı amacıyla yaygın olarak kullanılan anksiyeteyi artıran bir işlemdir ve Jones ve arkadaşlarının [15] yaptığı çalışmada endoskopi işlemi öncesi anksiyete düzeyinin anlamlı olarak arttığı bulunmuştur. Durumluk kaygı puanı o anki işlem ya da duruma ilişkin kaygıyı göstermektedir. Araştırmada eğitim verilen deney grubundaki bireylerin işlem sonrasında anlamlı derecede durumluk 
kaygılarında azalma gözlemlenirken $(p<0.05)$, eğitim verilmeyen kontrol grubundaki bireylerde işlem sonrasındaki kaygıları işlem öncesi ile benzer düzeyde görülmektedir $(p>0.05)$ (Tablo 3 ). Bu farkın deney grubuna işlem öncesi verilen eğitimden kaynaklandığı, bu da verilen eğitimin hastaların kaygılarını azaltmada etkili olduğunu bize göstermektedir. Pornthawee ve Nuthapong [16], Ratanalert ve arkadaşlarının [17] yaptığı çalışmalarda da bulgularımızla benzer şekilde işlem öncesi verilen hasta eğitiminin bireylerin durumluk kaygısını azaltmada etkili olduğu görülmüştür. Endoskopi dışında farklı tanı işlemlerinde de hastaların farklı nedenlerle kaygı yaşadığı ve eğitimle birlikte bu kaygılarında azalma olduğu saptanmıştır. Ekiz ve Göz'ün [18] koroner anjiografi uygulanacak hastaları bilgilendirmenin kaygı düzeyine etkisini belirlemek için yaptığı çalışmada, bilgilendirilen gruptaki hastaların kontrol grubundaki hastalara göre kaygı puan ortalamasının anlamlı olarak daha düşük olduğu belirlenmiştir. Yine Tel ve arkadaşlarının [19] manyetik rezonans görüntüleme uygulanacak hastalara yapılan sözlü bilgilendirmenin kaygı düzeyine etkisini belirlemek için yaptıkları çalışmada da, bilgilendirilen gruptaki hastaların kaygı düzeyinin kontrol grubundaki hastalara göre anlamlı olarak daha düşük olduğu belirlenmiştir.

Sürekli kaygı düzeyi bireyin sadece mevcut durumundan değil, yaşam şekli, kişilik özelliği gibi koşullardan da etkilenir. Araştırmada sürekli kaygı düzeyleri incelendiğinde, deney grubundakilerin işlem sonrası sürekli kaygı puanları, işlem öncesine göre azalmıştır. Kontrol grubunda ise, işlem sonrasında işlem öncesine göre minimal düzeyde azalma gözlenmiştir $(p>0.05)$ (Tablo 3). Deney grubunda verilen eğitimin o anki işleme yönelik olması nedeniyle bireyin sürekli kaygı düzeyinde belirgin değişiklik oluşturmaması beklenen bir sonuçtur [20]. Hem deney hem kontrol grubundaki minimal azalmanın işlemin bitiminden kaynaklanan rahatlamaya bağlı olabileceği düşünülmektedir. Ertem ve ark.'nın [21] ile Ceyhan ve ark.'nın [22] yaptığı çalışmalarda da işlem öncesi verilen eğitimin durumluk kaygı düzeylerini azalttığı, sürekli kaygı düzeylerinde önemli değişiklik oluşturmadığı belirlenmiştir ( $p>0.05)$.

Araştırma kapsamındaki deney ve kontrol grubunun cinsiyete göre işlem öncesi ve sonrası durumluk-sürekli kaygı puanları incelendiğinde; işlem öncesi ve sonrası durumluk-sürekli kaygı düzeyinde anlamlı bir fark bulunmazken $(p>0,05)$, her iki grupta da erkeklerin kaygı düzeyi daha düşük bulunmuştur. Bu bulgular kadınların bağımsızlıklarını kaybetme duyguları, hastalıklarıyla ilgili olumsuz düşünceleri, ailesine bakma sorumlulukları göz önüne alındığında erkeklerden daha fazla kaygı yaşamalarına neden olduğunu düşündürmektedir. Bulgularımızla benzer şekilde Trevisani ve ark.'nın [23], Bal'ın [24], Marakoğlu ve ark.'nın [25] ve Karabulut ve ark.'nın [26] yaptığı çalışmalarda da, endoskopi işlemi öncesi kadınların anksiyete puan ortalamalarının erkeklere göre daha yüksek olduğu bulunmuştur. Çalışmamız literatürle benzerlik göstermektedir.

Anksiyete her yaşta görülebildiği gibi, her yaş grubunda da farklı nedenlerle, farklı düzeylerde görülen bir durumdur. Araştırma kapsamına alınan bireylerin yaş grupları ile işlem öncesi ve sonrası durumluk-sürekli kaygı puanları arasında istatistiksel olarak anlamlı bir fark bulunmamıştır $(p>0,05)$. Ancak 20-29 yaş grubundaki bireylerin kaygılarının diğer yaş gruplarından daha yüksek düzeyde olduğu tespit edilmiştir. Ölüm korkusu, endoskopi işleminin sonucunun ne çıkacağı endişesi, hayatta kaybedecek çok şeyinin olduğunun düşünüldüğü bu yaşlarda anksiyetesinin yüksek olması beklenilen bir sonuçtur. Bu sonuçlar, Chuah ve ark.'nın [27] “Gastroskopi, kolonoskopi ve ERCP uygulanan hastaların genel anksiyete düzeyleri" adlı çalışmasında anksiyetesi yüksek olan grubun yaş ortalamasının düşük olduğu verisiyle benzerlik göstermektedir.

Bireyin eğitim durumu ne olursa olsun, yaşamını tehdit eden herhangi bir durum karşısında kaygı yaşayabilmektedir. Çalışmada deney ve kontrol grubundaki bireylerin eğitim durumlarıyla işlem öncesi ve sonrası durumluk kaygı düzeylerine bakıldığında durumluk kaygılarında anlamlı bir fark bulunmazken, deney grubundaki bireylerin sürekli kaygılarında işlem sonrasında anlamlı bir düşüş görülmüştür $(p<0,05)$. Bu anlamlılığı diğer eğitim seviyelerine göre işlem öncesi ve sonrası en düşük kaygı seviyesine sahip olan lise ve üzeri eğitim seviyesindeki kişilerden kaynaklandığı saptanmıştır. Benzer şekilde Bal'ın çalışmasında da [24], bireylerin işlem öncesi anksiyete puanlarına bakıldığında, 
yüksekokul ve üniversite mezunlarının en düşük anksiyeteye sahip oldukları görülmüştür. $\mathrm{Bal}$, eğitim düzeyi ve anksiyetenin ters orantılı oluşunu; yüksek eğitimli hastaların anksiyete ve başetme mekanizmalarını kullanmada daha ilgili, yeni bilgilere daha açık ve uyumlu olmaları şeklinde açıklamıştır.

Deney grubundaki bireylerin mide ağrısı ön tanısıyla gelenlerin durumluk kaygıları, kontrol grubundaki bireylerde ise gastrit tanısı alanların sürekli kaygıları daha yüksek gözlenmiştir. Ancak ön tanılarıyla kaygı düzeyleri arasında anlamlı farklılık gözlenmemiştir $\quad(p>0.05)$. Mide ağrısı şikâyeti henüz kesinleşmemiş bir ön tanı olduğu için birçok hastalığın belirtisi olabileceğinden durumluk kaygıyı artırdığı düşünülebilir. Gastrit tanısı bireyin uzun süreli onunla yaşamasını gerektiren bir durum olduğu ve gastrite stresli yaşam-kişilik özelliğinin etki ettiği düşünülürse sürekli kaygılarının yüksek olması beklendik bir sonuçtur.

Bireylerin daha önceden işlem hakkında bilgi almaları, kimi zaman var olan durumla karşılaştıklarında etkin olarak baş edebilmelerini sağlayabildiği gibi, önceki bilgileri nedeniyle korku ve kaygı yaşamalarına da neden olabilir. Çalışmada deney ve kontrol grubunda işlem hakkında bilgi alan bireylerin durumluk kaygı düzeyleri işlem öncesinde bilgi almayanlara göre daha yüksek bulunurken, her iki grupta da işlem sonrasında durumluk-sürekli kaygı azalma göstermiştir $\quad(p>0.05)$. Bireylerin işlem hakkında bilgilerinin olması kendi yaşantılarında oluşturabilecekleri değişiklikleri ve hastalığın ciddiyetini kavrayarak işlem öncesi kaygı düzeylerinin artmasına neden olabilir. Sidar ve ark.'nın [28] yaptığı çalışmada ise, hastalıkları hakkında bilgi alan bireylerin kaygı puan ortalamalarının daha düşük olduğu, fakat aradaki farkın istatistiksel olarak anlamlı olmadığı görülmüştür.

Sonuç olarak, çalışmada hastalara işlem öncesi verilen eğitimin durumluk kaygıyı azaltmada etkili olduğu saptanmıştır. $\mathrm{Bu}$ da bize eğitimin kaygı düzeyi üzerine olumlu etki yaptığını göstermektedir. Bunun için hastaların kaygılarını azaltmak, bireye yapılacak her işleme uyumunu artırmak ve oluşabilecek komplikasyonları önlemek için işlem öncesi hastalara eğitimlerin verilmesi, mümkünse görsel materyallerle eğitimlerin desteklenmesi önerilebilir.
Çıkar İlişkisi: Çalışmada yazarlar ile iliği her hangi bir çıkar ilişkisi ve çatışması bulunmamaktadır.

\section{Kaynaklar}

1. Tuncer MM. Diagnostik ve terapötik üst gastrointestinal endoskopi. i.Ü. Cerrahpaşa Tıp Fakültesi Sürekli Tıp Eğitimi Etkinlikleri 2004;38:77-87.

2. Illter T. Gastrointestinal sistem endoskopisi. In: Illiçin G, Biberoğlu K, Süleymanlar G, Ünal S. edit. İç Hastalıkları Kitabı. Cilt 1. 2.baskı. Güneş Kitabevi, 2003;1487-1491.

3. Azap A, Sözen TH. Endoskopik girişimler ve infeksiyon. Özden A, Sahin B, Yılmaz U, Soykan İ. edit. Gastroenteroloji. 1.Baskı. Fersa Matbaacılık Ltd. Şti, 2002;869-873.

4. Karahan Ö. Cingi A. Gastrointestinal sistem endoskopisi. Pelin Ofset Tipo Matbaacılık ve Tic. Ltd. Şti,2016;35-41.

5. Hülagü S. Gastroenteroloji kliniğinin Kuruluşu. SKOP Gastrointestinal Endoskopi Dünyası 2011;6:6-12.

6. Jalocha L, Wojtun S, Gıl J. Complications of endoscopic procedures. Pol Merkur Lekarski 2004;17:87-89.

7. Eıssen GM, Baron TH, Domınıtz JA, et al. Guideline on the management of anticoagulation and antiplatelet therapy for endoscopic procedures. Gastrointest Endosc 2002;55:775-779.

8. Yamada T, Alpers DH, Owyang C, Powell DW, Silverstein FE, Hasler WL. Endoskopi. Gastroenteroloji El Kitabında. Dursun AN (çeviri editörü).1. Baskı. İstanbul: AND Danışmanlık ve Yayıncılık, 2002;667679.

9. Classen M. Informed consent for gastroenterological endoscopy. In: Classen M, Tytgat GNJ, Lightdale CJ. eds. Gastroenterological Endoscopy. Thieme: New York,2002;72-79.

10. Faigel DO, Eisen GM, Baron TH, et al. American society for gastrointestinal endoscopy. Preparation of patients for $\mathrm{Gl}$ endoscopy. Gastrointest Endosc. 2003;57:446-450

11. Cohen J, Safdi MA, Deal SE, et al. Quality indicators for esophago gastroduodenoscopy. Am J Gastroenterol 2006;101:886-891.

12. Abuksıs G, Mor M, Segal N, et al. A patient education program is cost-effective for preventing failure of endoscopic procedures in a gastroenterology department. Am J Gastroenterol 2001;96:1786-1790.

13. Öner N, LE Compte A. Süreksiz Durumluk/Sürekli Kaygı Envanteri El Kitabı.1.baskı. Bogaziçi Üniversitesi Yayınları, İstanbul 1983.

14. Uçan Ö, Ovayolu N, Savaş CM. Üst gastrointestinal sistem endoskopisi işleminde dinletilen müziğin hastaların bazı değerlerine, memnuniyetine ve işlemin başarısına etkisi. Atatürk Üniversitesi Hemşirelik Yüksekokulu Dergisi 2007;10:16-26. 
15. Jones MP, Ebert CC, Sloan T, et al. Patient anxiety and elective gastrointestinal endoscopy. J Clin Gastroenterol 2004;38:35-40.

16. Riddhiputra P, Ukarapol N. Effect of systematic psychological preparation using visual illustration prior to gastrointestinal endoscopy on the anxiety of both pediatric patients and parents. J Med Assoc Thai 2006;89:231-235.

17. Ratanalert S, Soontrapornchai $P$, Ovartlarnporn B. Preoperative education improves quality of patient care for endoscopic retrograde cholangiopancreatography. Gastroenterol Nurs. 2003;26:21-25

18. Ekiz S, Göz F. Koroner anjiografi öncesi hastaları bilgilendirmenin anksiyete düzeyi üzerine etkisinin değerlendirilmesi. Atatürk Üniv. Hemşirelik Yüksekokulu Dergisi 2005;8:20-30.

19. Tel H, Tel H, Alp F, Öztoprak İ. Manyetik rezonans görüntüleme $(\mathrm{mrg})$ uygulanan bireylere yapılan bilgilendirmenin işlem öncesi ve işlem sonrası anksiyete düzeyine etkisi. Hacettepe Üniversitesi Hemsirelik Yüksekokulu Dergisi 2004;11:65-73.

20. Öner N. Durumluluk ve Sürekli Kaygı Envanterinin Türk Toplumunda Güvenilirliği ve Geçerliliği. Doçentlik Tezi, Hacettepe Üniversitesi Sağılı Bilimleri Enstitüsü;1997,Ankara.

21. Ertem A, Yava A, Demirkılıç U . Kardiyak cerrahi yapılan hastaların ameliyat öncesi verilen aydınlatılmış onam hakkındaki görüş ve önerilerinin belirlenmesi. Türk Göğüs Kalp Damar Cerrahisi Dergisi 2013;21:378-391.

22. Ceyhan Ö, Taşcı S, Tokmakçı M. Modeling the effects of education with artificial neural networks on anxiety level of coronary angiography patients: A randomized controlled trial. Asian Pac. J Health Sci. 2017;4:67-72.

23. Trevisani L, Sartory S, Putinati S. et al. Assessment of anxiety levels in pattients during diagnostic endoscopy. Recenti Prog Med. 2002;93:240-244.

24. Bal V. Şok dalgaları ile taş kırma (Ekstracorporeal shock wave lithotripsy-ESWL) işleminde ağrı ve anksiyete düzeyi üzerine müziğin etkisi. Yüksek Lisans Tezi, Genel Kurmay Başkanlığı Gülhane Askeri Tıp Akademisi Sağlık Bilimleri Enstitüsü,2002,Ankara.

25. Marakoğlu I, Özdemir D, Demirer S, Sezer H. Periodontal tedavi öncesi durumluk ve sürekli kaygı düzeyi. C.Ü. Diş Hekimliği Fakültesi Dergisi 2003;6:7379.

26. Karabulut N, Kılıç D, Köse S. Hipertansiyonlu bireylerde öfke ve anksiyete düzeyleri. Uluslararası İnsan Bilimleri Dergisi 2004;1303:1-8.

27. Chuah S.Y, Goh K.L, Wong N.W. Common anxieties of patients undergoing oesophago-gastro-duodenoscopy, colonoscopy and endoscopic retrograde cholangiopancreotography. Med J Malaysia 1999;54:216-224.
28. Sidar A, Dedeli Ö, İşkesen Aí. Açık kalp cerrahisi öncesi ve sonrası hastaların kaygı ve ağrı distresi: ağrı düzeyi ile ilişkisinin incelenmesi. Yoğun Bakım Dergisi 2013;4:1-8.

\section{Teşekkür}

Çalışmanın yapılması için verilerin toplanmasında ve hasta uygunluğunda desteğinden dolayı servis hekimlerine ve hemşirelerine teşekkür ederiz 